\title{
Counterfactual Thinking and Functional Differences in Depression ${ }^{\dagger}$
}

\author{
Ana Cristina Quelhas, ${ }^{1}$ Mick J. Power, ${ }^{2 *}$ \\ Csongor Juhos ${ }^{1}$ and Jorge Senos ${ }^{1}$ \\ ${ }^{1}$ Instituto Superior de Psicologia Aplicada, Lisbon, Portugal \\ ${ }^{2}$ Edinburgh University, Edinburgh, UK and Department of Psychology, \\ University of Tromsø, Norway
}

\begin{abstract}
The purpose of the studies reported in this paper was to evaluate the function of counterfactual thinking (CT) in depression. In Experiment 1, depressed and non-depressed participants were asked to imagine themselves as the protagonist of a hypothetical situation, and to think counterfactually about three different scenarios. The results showed that there was a similar CT style (in terms of direction, structure and focus of mutation) for the depressed and the nondepressed groups. It was also found that the perceived preparation for a future similar situation increased after CT and, contrary to our hypotheses, this effect was observed in both groups. In Experiment 2 , a real-life situation was used (a course examination) in which participants experienced a negative outcome (a poor score on the test). Again, it was observed that depressed and non-depressed participants showed the same CT style, but non-depressed participants were more likely to use CT spontaneously. In addition, the second study showed further differences between the two groups: depressed participants not only showed a lack of cognitive benefits from thinking counterfactually (i.e., after CT they do not feel more prepared for future similar events, nor able to avoid a similar bad outcome, in contrast to the non-depressed participants), but also show a lack of behavioural changes (both intentions to change and actual changes over the subsequent week). In conclusion, these results provide evidence about the function of CT both in depressed and in non-depressed thinking, and highlight both the similarities and differences for these two groups. Copyright $\odot 2008$ John Wiley \& Sons, Ltd.
\end{abstract}

\section{INTRODUCTION}

The aim of this research was to begin to understand the function of counterfactual thinking (CT)

\footnotetext{
${ }^{+}$This research was partially supported by the European Program POCTI/PSI/42215-FEDER-FCT. Preliminary results were presented at the Fifth National Symposium of Research in Psychology, Lisbon 2003, and at the 9th International Conference on Motivation (EARLI) in 2004.

* Correspondence to: Prof Mick Power, Clinical and Health Psychology, Edinburgh University, Medical School, Teviot Place. Edinburgh EH8 9AG, UK.

E-mail: mjpower@staffmail.ed.ac.uk
}

in depression. We agree with Roese and Olson (1995a, p.626) when they said, 'depression and other dysphoric states may be associated not with preparative thinking but with afunctional, perhaps even dysfunctional, rumination'. However, although there is an increasing accumulation of evidence in support of the importance of rumination in depression and other psychopathology (e.g., Harvey, Watkins, Mansell, \& Shafran, 2004; Nolen-Hoeksema, 2000), there is little or no empirical support in the literature for this hypothesis specifically in relation to the putative function of $\mathrm{CT}$ in depression. 
There is now a considerable literature on the relationship between thinking and depression that has accumulated over several decades, and that represents several different approaches to the relationship between thinking and depression (e.g., see Power \& Champion, 1986; Power \& Dalgleish, 2008). Some of these approaches were developed solely in the clinical context (e.g., Beck, 1976) and therefore show a lack of integration of the most recent advances in cognitive psychology. These clinical-based approaches typically present an inappropriate view of, for example, reasoning in ordinary healthy individuals, and, consequently, can fail to see similarities as well as differences between reasoning in depression and reasoning in non-depressed individuals (see Champion \& Power, 1995; Power \& Champion, 1986; Power \& Wykes, 1996; Quelhas \& Power, 1991), or of reasoning in schizophrenia (e.g., Quelhas, 1987). Just to give an example, the idea that healthy non-depressed individuals reason in a logical way (e.g., see proposals by Beck, 1976, in the case of depression; Arieti, 1974 and Matte-Blanco, 1976, in the case of schizophrenia) leads to the incorrect view that reasoning performance by comparison is almost always biased in such patients.

In contrast to the clinically based views of distortion and bias in depression, Alloy and Abramson (1979) introduced a contrasting switch in the general assumption of cognitive distortions in depression. Based on a series of studies that employed a contingency judgment task, they observed that mildly depressed students were more accurate and more realisticthannon-depressed controls. Non-depressed participants showed a positive bias when judging that they had control over positive outcomes where in fact the control was illusory, whereas depressed participants in the absence of such bias were more realistic. Alloy and Abramson (1979) termed this phenomenon 'depressive realism'. In relation to these opposite views of depressive bias versus depressive realism, we have argued previously that both effects of apparent bias and of apparent realism are observable depending on different circumstances, task conditions and so on (e.g., Power, 1991; Power \& Dalgleish, 2008). For example, depressed individuals are likely to be more 'realistic' or accurate when rejecting false positive information and accepting true negative information, but more 'biased' when rejecting true positive information and accepting false negative information. Quelhas and Power (1991), in a study with a linear syllogism task, in which the valence of the information was manipulated, found that normal and anxious groups were significantly better at the positive syllogisms than at the negative, whereas the depressed group showed equal performance for both kinds of positive and negative problems. However, the fact that Quelhas and Power (1991) did not find a negative bias for the depressed group could have been due to the use of a mildly depressed student sample, as in the classic Alloy and Abramson (1979) study, instead of using severely depressed clinical individuals.

In summary, what we wish to call attention to in the area of cognitive psychopathology is the need for awareness of the advances in cognitive psychology and cognitive science. It is not possible to understand, for example, distortions in reasoning without knowing how ordinary healthy individuals reason, nor without considering how distortions are moderated by context. In fact, the study of CT is one of the areas where such an interaction is clearly plausible. However, despite the fact that CT has a considerable effect on people's expectancies, intentions and emotions (e.g., Roese \& Olson, 1995b), there is very little known about the consequences of $\mathrm{CT}$ in the context of emotional disorders like depression. In the next section therefore, we present the main findings from the area of CT and advance a theoretical speculation about the (a)functionality of counterfactuals in the case of depressed individuals.

Counterfactual thoughts about what might have been, if only something might happen in a different way, are very common when something undesirable happens (e.g., 'If I had taken the usual route for work, I would have avoided the car accident'). Mainly in the domain of socio-cognition, psychologists have been interested in understanding the cognitive, social, motivational and emotional consequences of such thoughts (for a review see, for example, Roese, 2005; Roese \& Olson, 1995b). More recent work, based on mental models theory (e.g., Byrne, 1996, 1997; see also Byrne, 2005, for a review in this domain; Johnson-Laird, 2006), has also drawn attention to the need to consider the types of mental representations and cognitive processes involved in CT. In relation to the function of counterfactual thought, Roese (1994) has drawn attention to two different functions that depend on the so-called direction of the thoughts: first, thoughts with an upward direction, that is, counterfactuals about how the situation could have resulted in a better or improved state of affairs; and second, thoughts with a downward direction, that is, counterfactuals about how the situation could have turned out worse than it did. According to Roese, upward counterfactuals serve a preparatory function in that identification of the cause of 
a negative outcome or some other factor that could have avoided the unfortunate situation (Mandel, 2003; Mandel \& Lehman, 1996) and imagining how things could have been better, may prepare us for future similar situations. On the other hand, downward counterfactuals are considered to serve an affective function (the comparison between what happens in fact, and how things could have been worse, should help people to feel better). According to Roese and Olson (1997) upward counterfactuals are more useful because they point to improvements in the status quo, whereas downward counterfactuals point to the maintenance of the status quo.

In general, people generate more upward counterfactuals, but it seems that when they are in a good mood they generate downward ones in addition (e.g., Sanna, Turley-Ames, \& Meier, 1999). So, should we expect that depressed individuals make more upward counterfactuals? And if they do, will those thoughts serve a preparatory function, as observed in the case of non-depressed individuals? Or should we expect that '... dysphoric individuals may intentionally consider downward possibilities in order to make themselves feel better', as Roese and Olson (1995c, p.38) stated? We will return to these possibilities later.

One of the underlying mechanisms of CT is causal inference. Identifying the cause responsible for a negative outcome is useful because it may help to avoid a future negative outcome in a similar situation (Roese \& Olson, 1997). Counterfactual thoughts generally suggest successful future action and, consequently, contribute to enhanced expectancies of personal efficacy, personal control and confidence in general (McMullen, Markman, \& Gavanski, 1995). In this account the benefits of CT are narrowly bounded to vision of a successful future, where a capable agent executes actions in order to enhance performance. However, in depression, people do not see themselves as capable rather as inept, weak, defective and hopeless about their personal future (e.g., Beck, Rush, Shaw, \& Emery, 1979). They tend to identify causes of negative outcomes, features of their own faulty personality or diseased body. The dark picture of a negative self-image is completed by the conviction that they do not have the necessary attributes to reach success in the future (Beck et al., 1979; Kovács \& Beck, 1978).

It seems plausible that individuals who have a chronic negative view of future events may not elaborate the same kind of performance-enhancing strategies in their counterfactual thoughts as people who do not suffer depression. The process might be compromised at the beginning. To enhance performance and avoid future negative outcome, the right cause must be identified for a particular consequence. Nevertheless, depressed people show a consistent bias in their causal attributions (Seligman, Abramson, Semmel, \& von Baeyer, 1979; Sweeney, Anderson, \& Bailey, 1986; Weary \& Edwards, 1994). Individuals with a depressive attributional style, when confronted with a negative outcome tend to identify causes that they perceive as uncontrollable, internal, stable and global. In other words, depressed people frequently perceive the causes of negative events as features of their character or native abilities. Thinking counterfactually about features that cannot be easily changed has no cognitive or behavioural benefit. It may even become self-defeating when a counterfactual related negative emotion like guilt is erroneously directed to the self (Alicke, 2000; Davis, Lehman, Silver, Wortman, \& Ellard, 1996; Janoff-Bulman, 1979; Sherman \& McConnell, 1995). This scenario is most likely to occur in severely depressed individuals whose motivation may be low to seek for control in different aspects of their lives. Individuals who suffer from high levels of depression frequently believe that there is nothing that they can do to change their outcomes (Marsh \& Weary, 1994). The perception of almost total lack of control may result in feelings of hopelessness, in passivity, and in social isolation (Abramson et al., 2002). Nevertheless, at lower levels of depression the generalized concerns about control may result in heightened control motivation (e.g., Weary, Elbin, \& Hill, 1987). In terms of CT, as Markman and Weary (1998) have shown, attempts to render the social environment more controllable and predictable yield an enhanced tendency to engage in controllable $\mathrm{CT}$, and individuals experience an increase in the retrospective perception of control. However, in a recent study, Markman and Miller (2006) found that individuals who endorse a relatively mild-to-moderate depressive symptom level gain no psychological benefit from focusing on how they could have prevented a negative outcome. It seems that with an increase in depression level, upward counterfactuals become more and more dysfunctional, that is, more uncontrollable and more characterological in the Janoff-Bulman (1979) sense, in which guilt is related to aspects of the self and actions by the self.

Our main interest in the present studies is to evaluate the possible function of CT in depression. In a previous study that used hypothetical 
scenarios (Juhos, Quelhas, \& Senos, 2003), and in which we were interested in counterfactual style and feelings of preparation, we found that dysphoric and non-dysphoric participants endorsed the same kind of counterfactual thoughts: upward direction, with a subtractive structure and a selfreferent focus of mutation. We also observed that after CT participants reported that they feel more prepared for future similar situations in comparison with participants who thought factually about the same scenario. What was surprising was that we observed similar results for both dysphoric and non-dysphoric participants, in relation to the perception of feelings of preparation following the process of engaging in CT. The fact that we did not observe any differences between dysphoric and non-dysphoric participants leads to the hypothesis that these results could be a consequence of the sample used (dysphoric students instead of clinical patients), or the possibility of a methodological problem with the approach used (e.g., that the scenarios were not sufficiently engaging). In an attempt therefore to clarify the possible functional and dysfunctional implications of counterfactuals at the emotional and at the cognitive levels, we carried out the two following experiments in order to test a number of these interpretations.

\section{EXPERIMENT 1}

In this experiment, participants were given three different scenarios to induce $\mathrm{CT}$, in order to evaluate if CT could be moderated by the context of a story. We also gave a number of questions to participants in order to evaluate the following aspects of the story: the perceived control of the situation; the direction of CT; the affect associated with CT; the perceived preparation for future similar situations; and the perceived valence of the result. Our aim was to compare depressed and non-depressed participants' counterfactual thoughts and their cognitive and affective consequences. Our prediction was that the two groups would not differ in the kind of counterfactual thoughts made, but would differ in the consequences of thinking counterfactually (e.g., for depressed participants we predicted a lack of preparative benefit from engaging in upward CT).

\section{Sample}

From a population of 439 students of the first year of psychology at the Instituto Superior de Psico- logia Aplicada (ISPA; Lisbon), we chose a sample based on the Beck Depression Inventory (BDI) results of 124 students ( 94 female, 30 male). The average age in the sample was mean $(\mathrm{M})=19.7$; standard deviation $(\mathrm{SD})=3.5$. Seventy participants who endorsed minimum BDI scores constituted the non-depressed group $(\mathrm{M}=0.5 ; \mathrm{SD}=0.5)$ and 54 individuals who scored more than 14 formed the depressed group $(M=19.7 ; \mathrm{SD}=5.2)$.

Together with the BDI, we used the Spielberger State-Trait Anxiety Inventory (STAI Form Y-1) in order to assess individuals with high levels of anxiety among the depressed group. However, given the correlation $(r=0.56 ; p<0.05)$ between the results on BDI and STAI, it was not possible to obtain a depressed group with low levels of anxiety.

\section{Materials}

We constructed three stories with different scenarios, but with the same structure. The structure of each story was: first paragraph is the introduction that gives the idea of the scenario; second paragraph is a first antecedent in which the protagonist of the story has control, i.e., something happens that is a consequence of the protagonist's decision; third paragraph is a second antecedent in which the protagonist has no control; and the fourth paragraph is the consequent, i.e., something unpleasant happens that is not very drastic, in order that people can think about how things could have been better or worse.

The complete stories can be seen in Appendix A. Story 1 is about two students making love without using a condom; Story 2 is about a student who failed to get an important paper to study for an examination; and Story 3 is about a relationship separation during the summer in order to test the strength of the relationship.

We used each story in two different tasks: a thought-listing task and an evaluation task. In both of the tasks the story was followed by an instruction that was designed to produce CT. In the thoughtlisting task, participants were invited to write down their thoughts about how things could have been different, if something had happened in a different way. In the evaluation task participants provided answers to questions about the perceived control in the situation; the CT direction (upward versus downward); the affect associated with the CT (negative-positive; feeling bad-feeling well; sad-happy); the perceived preparation for similar future situations; and the perceived valence of the result. 


\section{Procedure}

Data were collected in groups, in three classrooms. Each participant carried out both of the tasks (the thought-listing task and the evaluation task) with each of the stories. The order of the stories was constant and the order of tasks was counterbalanced. At the end of the block they were given the STAI $\mathrm{Y}-1$ and the BDI.

\section{Results Analysis}

For the results analysis we have eliminated the outliers. The analysis of the direction of the CT was based on results obtained when participants had to write down their thoughts.

We also have an analysis based on the participant's CT type. This is a variable that we created that was based on the kind of CT direction produced, with four levels: no CT; only downward CT (downward style); upward and downward CT (mixed style); and only upward CT (upward style).

In general, participants produced more upward than downward CT $(F[1,115]=88.98 ; p<0.001)$. This main effect of CT direction is qualified by two variables: the level of depression and the given order of material. Non-depressed participants gave more upward than downward CT $(F[1,115]=$ 92.24; $p<0.001)$, but so did depressed participants $(F[1,115]=16.31 ; p<0.001)$. However, upward CTs were more frequent with non-depressed than with depressed participants $(F[1,115]=9.20 ; p<$ 0.001 ), whereas with downward CT there were no significant differences.

Related with the order of the material, it was possible to see that participants produced more downward CTs when they received the stories with the questions first, followed by the stories with space to write their thoughts, than in the reverse order $(F[1,115]=7.19 ; p<0.01)$.

All analyses above were made with frequencies of upward and downward CT. And all analyses below were made with the CT type. So, as independent variables we have: depression; CT type; and kind of story (a repeated measure), and each dependent variable (associated affect; preparative function; perceived control; result valence) being analysed separately in order to examine the effects of these factors.

In relation to the associated affect, the three items of this question were well correlated (with group Cronbach alphas for the items between 0.90 and $0.93)$, so we used the mean values for the analyses.
We obtained only a main effect of CT type $(F[3,77]$ $=4.70 ; p<0.01)$, that is, upward CT was found to be associated with a more negative affect than were all the other CT types.

Regarding preparative function, we found a main effect of the Story $(F[2,218]=7.57 ; p<0.001)$. Participants thought that they would be more prepared for future similar situations for all three stories because all means were above 4 (on a seven-point scale). However, they felt more prepared in the case of Story 1, than with the other stories ( $F[2$, $218]=7.57 ; p<0.001)$. Unfortunately, it is difficult to draw any firm conclusions about the differences between the stories because the stories were presented in a fixed order so as to ease administration to different size groups of students, when the stories preferably should have been counterbalanced for order. So, this main effect could be due to the Story content or to the fact that it was the Story order effect.

In relation to the perceived control variable, we found a main effect related to the Story $(F[2,216]$ $=23.70 ; p<0.001$ ). More control was perceived for Story 1 than for Story $2(F[1,108]=9.97 ; p<0.001)$; and for Story 2 than for Story $3(F[1,108]=14.96$; $p<0.001)$. There is also a marginal effect related to the CT type $(F[3,108]=2.22 ; p<0.09)$, in which there is a trend towards downward CT type being related to lower control. Comparing this group with individuals with an upward CT type we have $(F[1,108]=3,86 ; p<0.05)$. Considering that it is a one-tailed prediction, we can divide the $p$ value by two, and we get a clearly significant difference $(p<0.026)$. In sum, we can say that the upward CT type is associated with greater perceived control than the downward CT type.

Finally, in relation to the result valence, we found an interaction between the CT style and depression $(F[3,110]=2.85 ; p<0.04)$. There was a significant difference between depressed and non-depressed participants, within downward CT style $(F[1,110]$ $=7.52 ; p<0.01)$ : depressed participants rated the consequences of the stories to be more negative than non-depressed participants rated them.

In sum, Experiment 1 showed that depressed and non-depressed participants tend to generate more upward than downward counterfactual thoughts overall, but that upward thoughts were even more frequent with non-depressed than with depressed participants $(F[1,115]=9.20 ; p<0.001)$, whereas with downward CT there was no significant difference.

We also found that an upward CT type is associated with greater perceived control than down- 
ward CT type, which is congruent with Roese and Olson's (1995a) idea that upward counterfactuals are more frequent following controllable outcomes, and downward counterfactuals are more frequent following uncontrollable outcomes.

On the other hand, it was observed that depressed people found the results of the stories to be more negative than non-depressed people did. Unfortunately, however, this study did not allow for the detection of differences between depressed and non-depressed participants in relation to the perceived preparation for a future similar situation, after engaging in CT. In Experiment 2 therefore, we changed some methodological aspects of the study with the aim of improving our understanding of the function of $\mathrm{CT}$ in depression.

\section{EXPERIMENT 2}

In this second experiment, a number of methodological problems were obviated from the first study. The second experiment also substituted the use of hypothetical scenarios for a real situation, that of college examinations, in which participants could experience failure. The idea was to prevent the emotional distancing that can occur when people think about a hypothetical scenario, or the temporal distancing that can occur when they think about something bad that has happened in the past (the two situations normally used in CT studies). Also, the evaluation of CT consequences in the second experiment included not only the cognitive level but the behavioural level as well.

In this more realistic approach, participants were asked to think counterfactually about something that had just happened to them after they received a poor score in a college examination. The aim was to analyse whether or not depressed mood state in some participants altered the effects of CT in relation to: emotions (general emotions: feeling good/ bad; positive and negative specific emotions), cognitions (feelings of preparation; feelings of being able to avoid a future negative result; intensity of intentions to change behavioural patterns), and behaviours (post-counterfactual changes in actual behaviour).

\section{Method}

\section{Sample}

Depressed and non-depressed participants were selected from a new pool of undergraduates at ISPA (Lisbon) that participated in the data col- lection protocol that included the BDI-II. A total of 63 students, 51 female and 12 male, were recruited to participate. Those with BDI-II scores between 0 and 5 were chosen for the non-depressed control group ( $n=40$; BDI-II $\mathrm{M}=3.08$; $\mathrm{SD}=1.63)$ and the depressed group were selected as those with a BDI-II score of 17 or more following guidelines for the BDI-II of a score over 16 being likely to indicate depression in contrast to the slightly lower score used in the first experiment that was based on the first version of the BDI $(n=23$; BDI-II M $=18.95$; $\mathrm{SD}=1.58$ ). In addition, the two groups excluded all students who had received a positive grade on the academic test, because this group were not of the same level of interest as the 'objective failure' group.

\section{Procedure}

Depressed and non-depressed undergraduates, who obtained a negative grade on an academic training test, were asked to write down five spontaneous thoughts regarding the negative event, immediately after receiving the poor result. Afterwards, they were induced to think counterfactually about how things could have been different. As dependent measures, we used general and specific emotions. We also measured feelings of preparation and feelings of capability of prevention of future similar events. Emotions were measured before the test, after the test, and after processing the situation counterfactually. Feelings of preparation and of capability of prevention were measured before and after counterfactual generation. As a third dependent variable, we measured the intensity of intentions to carry out preventative behaviours. A week after the first phase of the study, whether or not preventative behaviours had actually occurred was then evaluated. Figure 1 provides an overview of the key points for data collection.

\section{Material}

The material used in the study consisted of a booklet that contained the following: questions about general emotional state, rating scales for the intensity of specific emotions, for the feelings of preparation and the perceived capability of avoiding, and for behavioural intentions (first observation); in addition, there was also space for a list spontaneous thoughts (see more detailed description of material in Appendix B).

A week after the first observation, participants responded to a three-item questionnaire. We used the same items as on page 9 of the first question- 


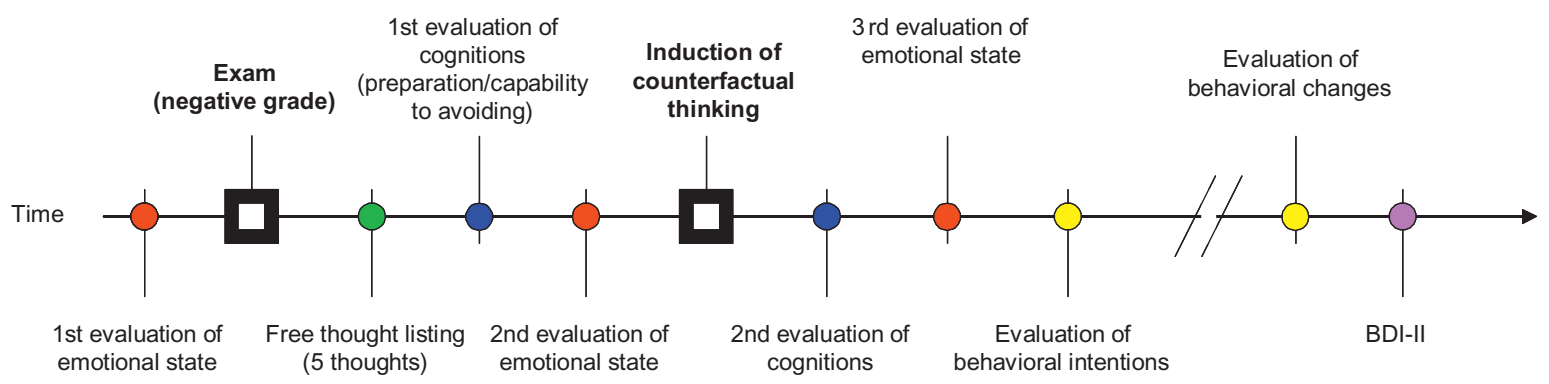

Figure 1. Time line of the procedure in Experiment 2

naire (see Appendix B), but this time participants evaluated changes in their behavioural patterns, that is, whether or not they had studied harder, worked harder in some other ways or used the course programme more than before the academic test. Nine-point rating scales were used for participants to respond.

\section{Results}

The five key areas analysed in this study were as follows: counterfactual style used in response to the exam failure; spontaneous counterfactual generation; the effects of CT on emotions, both general emotions and specific emotions; the effects of counterfactual generation on cognition, both feelings of preparation and feelings of ability to avoid future negative outcomes; and the effects of counterfactual generation on behavioural intentions and behaviour.

\section{Counterfactual Style}

Depression had no effect on counterfactual style. All of the observed counterfactuals had an upward direction and additional structure. Most of the participants, irrespective of their depression level, focused on controllable action (non-depressed group: 100\%; depressed group: $98 \%$ ).

\section{Spontaneous Counterfactual Generation}

Differences between the two groups for spontaneous counterfactual generation were analysed based on the proportion of counterfactuals among the thoughts listed after receiving the negative grade (number of counterfactuals/number of thoughts listed). The variable in question is not normally distributed, therefore the Mann-Whitney U-test was used. The results showed that depressed individuals have less tendency to activate counterfac- tual thoughts after experiencing a negative event in comparison with non-depressed individuals $(Z$ $=-2.08 ; p<0.04)$.

Participants with spontaneous counterfactual thoughts (that is, participants that made CT before they were ask to think counterfactually) were excluded from all the subsequent steps of analysis. Note that after participants listed their spontaneous thoughts their cognitions and emotions were evaluated, in addition to after listing their counterfactual thoughts. Therefore, the first measures for cognitions and emotions were used as baseline comparisons for the equivalent measures taken after participants thought counterfactually, which is why it was necessary to exclude individuals who made CT at the first step.

\section{Effects of CT on Emotions}

General Emotions. For this analysis we used a 2 (depressed-not depressed) $\times 3$ (time point of observation) $\times 2$ (general emotion type) repeated measures analysis of variance (ANOVA). We found a significant interaction between the time point of observation and the general emotion type $(F[2,104]$ $=16.25 ; p<0.001)$. In general, participants showed a better mood before the test situation than after, and they recovered their mood at least partly after engaging in CT. If the two groups of participants are analysed separately, the same pattern is found for depressed and non-depressed participants.

Specific Emotions. For this analysis we used a 2 (depressed-not depressed) $\times 3$ (time point of observation) $\times 12$ (emotion-specific) repeated measures ANOVA. Results revealed the main effect of emotion $(F[11,187]=7.89 ; p<0.001)$ that can be observed in Figure 2.

As can be seen in Figure 2, positive emotions tend to dominate, and among these emotions Hope is 


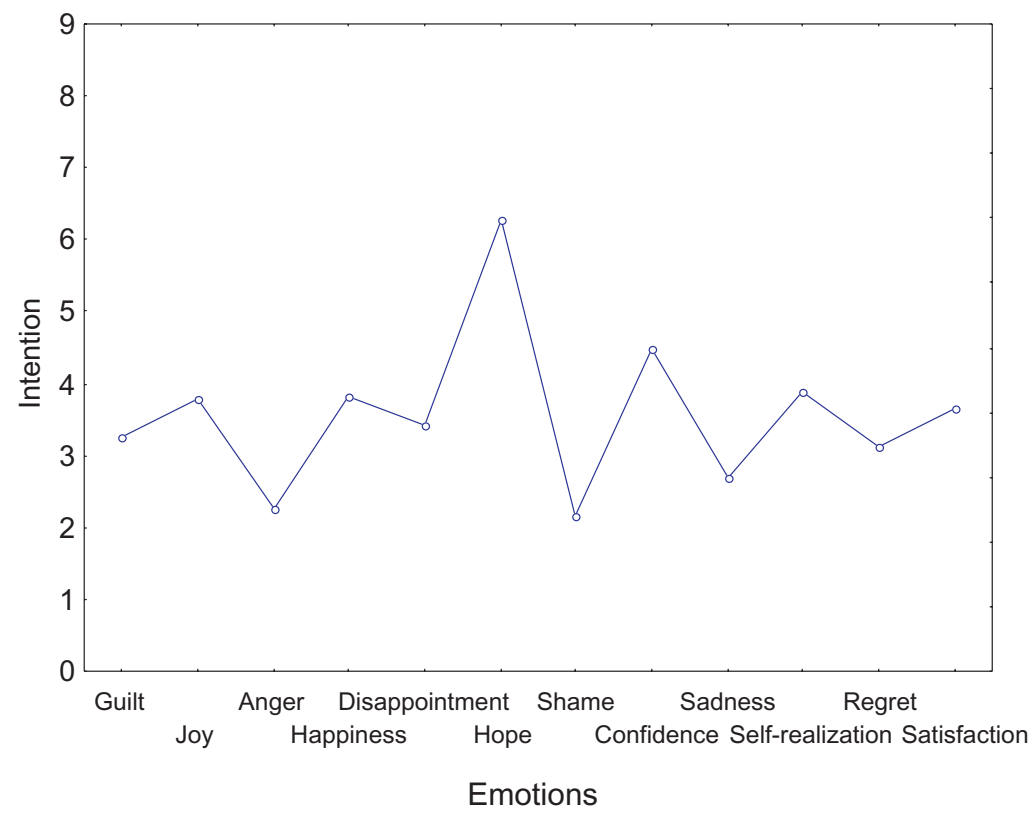

Figure 2. Main effect of specific emotions in Experiment 2

the strongest one. However, the results reveal an interaction between the time point of observation (time) and the type of emotion. Planned comparisons demonstrate the effect of time after the test for Disappointment (which increases, $F[1,17]=13.15$; $p<0.001$ ), Regret (increases, $F(1,17)=8.59 ; \mathrm{p}<.01$ ) Self-realization (which decreases, $F[1,17]=12.66 ; p$ $<0.001$ ) and Satisfaction (decreases, $F[1,17]=12.07$; $p<0.001$ ). Planned comparisons also demonstrated the effect for time after counterfactual, showing that the induced CT had a significant effect on Shame (decreases, $F[1,17]=6.701 ; p<0.02$ ) and Satisfaction (increases, $F[1,17]=6.427 ; p<0.02$ ). There were no differences between depressed and non-depressed participants with regard to the changes of intensity of specific emotions over time.

\section{Effects of Counterfactual Generation on Cognition}

There were a considerable number of participants who had justifications for feeling prepared and/or for feeling able to avoid a similar negative result in the future that had nothing to do with their CT. These participants were excluded from the following analyses so that the focus is on changes in cognition following CT.

Feeling Prepared for Next Time. For this analysis a 2 (depressed-not depressed) $\times 2$ (time point of observation) repeated measures ANOVA was used.
There was a main effect of time point of observation $(F[1,41]=4.94 ; p<0.03)$. The participants felt more prepared for future similar situations after engaging in CT than they did before. However, this pattern was significantly stronger for nondepressed participants; thus, planned comparisons confirm that, after counterfactual generation, nondepressed persons felt more prepared for the future $(F[1,41]=8.55 ; p<0.01)$ but depressed persons did not benefit significantly from the preparative effect of CT $(F[1,41]=0.37$; NS $)$.

Being Able to Avoid Negative Results in the Future. For this analysis a 2 (depressed-not depressed) $\times 2$ (time point of observation) repeated measures ANOVA was used. There was a main effect of time point of observation $(F[1,36]=4.46 ; p<$ $0.04)$. The participants felt more able to avoid a negative result in the future after processing the situation counterfactually. However, there are different patterns for depressed and non-depressed participants in relation to post-counterfactual feelings of preparation. Planned comparisons confirm that non-depressed individuals feel more able to avoid a future negative result after CT $(F[1,36]$ $=5.51 ; p<0.02)$, but depressed participants again did not show a significant effect $(F[1,36]=0.083$; NS). When the two groups were compared first in the pre-counterfactual situation and then in the 
post-counterfactual situation no differences were found $(F[1,36]=0.085$, NS; and $F[1,36]=0.685$, NS, respectively).

In sum, the results show that after CT nondepressed participants felt more prepared for future similar situations, and more able to avoid future similar negative outcomes than before $\mathrm{CT}$, but neither of these effects was found with depressed participants.

\section{Effects of Counterfactual Generation on Behaviour}

The participants evaluated eight behavioural intentions as follows: to study more; to work harder; to guide study by the course program; to hope for easier questions in the future; to be calmer during the test; to clarify doubts by asking the teacher; to use a different study method; and to be more attentive during the test.

A 2 (depressed-not depressed) $\times 8$ (type of intention) ANOVA of repeated measures was used to analyse the results. The analysis showed a main effect of type of intention $(F[7,371]=42.28, p<$ 0.001 ). As can be seen in Figure 3, the item with the lowest intention is the one that refers to 'easier test questions', which are out of the control of the individual. The ANOVA also showed that depression does not moderate these intentions but showed a non-significant interaction $(F[7,371]=1.07$; $p<0.38)$.
A week after the test, the participants were asked if they noted changes in their actual behaviour with regard to three items: studying, working and guiding study by the course program. The participants used a nine-point rating scale to evaluate the items, where 1 corresponded to 'I did it in the same way' and 9 'I did it a lot more'. A 2 (depressed-not depressed) $\times 3$ (behaviour type) ANOVA of repeated measures did not show any differences $(F[2,118]=0.45 ; p<0.64)$. There was no difference of any kind between the depressed and non-depressed participants.

The correlations were also checked between intentions and actual behavioural changes. The depressed group showed much lower correlations than the non-depressed group. In the depressed group there was no significant correlation between intentions and behavioural changes (study $r=0.02$; work $r=0.25$; use program $r=0.39$ ), but nondepressed subjects, who intended to work harder were more likely overall to convert their intentions into actual behaviour (study $r=0.27$; work $r=0.49$; $p<0.05$; use program $r=0.24$ ).

\section{GENERAL DISCUSSION}

In both studies presented here, as well as in a previous study (Juhos et al., 2003), an identical

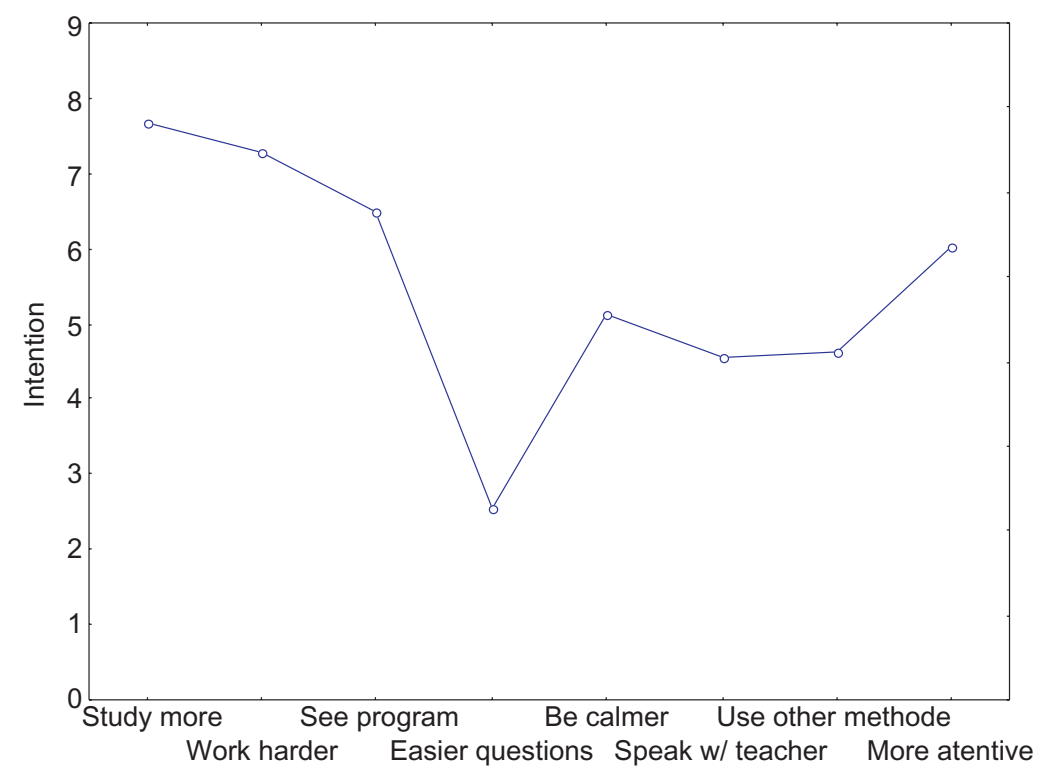

Figure 3. Main effect of type of behavioural intention in Experiment 2 
CT style has been found for depressed and nondepressed participants. What we have called CT style is defined by several characteristics of such thoughts, for example, their direction (upward or downward), their structure (additive or subtractive), their focus of mutation etc. The form of each characteristic may change between the different studies (e.g., in the Juhos et al., 2003), experiment a dominant subtractive structure was obtained, whereas in the second experiment in the present paper a dominant additive structure was obtained), but these changes are always in the same direction for the depressed and the non-depressed samples. Hence, when CT is activated, both depressed and non-depressed participants show an identical form for such thoughts.

Another interesting point for comparison between the two groups is related to the spontaneous activation of CT. Our second experiment allowed an analysis of spontaneous CT, because prior to participants being induced to think counterfactually about how things could have been different, they were asked to write down five spontaneous thoughts about the real negative event that they had just experienced (failure in their course examination). Results showed a significant difference between the two groups in that non-depressed participants showed a greater tendency towards spontaneous counterfactual generation in comparison to depressed participants. In sum, the results show that although depressed and non-depressed participants have an identical CT style non-depressed participants show a greater tendency for the spontaneous activation of this kind of thought (Experiment 2).

These observations do not fit the idea that mildly depressed individuals intentionally consider downward possibilities in order to make themselves feel better as Roese and Olson (1995c, p.38) supposed, nor the idea that they are more prone to do CT of an upward direction, or even that they have a propensity for CT (Monroe, Skowronski, MacDonald, \& Wood, 2005). Nevertheless, Kocovski, Endler, Rector, and Flett (2005) found that individuals high in social anxiety recorded more upward counterfactual thoughts than those low in social anxiety. It would be interesting to investigate if this result is mediated by the kind of anxiety, or if it could be generalized, because in the latter case, and given the association of depression with anxiety, a similar effect should be found in depression. But our results do not exclude the hypothesis of Monroe et al. (2005) that when depressed individuals engage in $\mathrm{CT}$, it could con- tribute to heightened feelings of regret. That could be another aspect of the dysfunctional role of CT in depression that matches with the superiority of post-decisional regret, observed by the authors, with mildly depressed students.

Another interesting finding from the study by Juhos et al. (2003) concerned how emotions (guilt and shame) were evaluated after the participants' counterfactual thoughts. According to the literature (see for example Roese \& Olson, 1997), upward counterfactuals should induce more negative emotions because reality is worse than the possible worlds considered in the counterfactuals. However, Juhos et al. (2003) found that both types of thoughts (i.e., factuals and counterfactuals) in their study generated identical negative emotions. For this reason we think that a possible misleading factor in other studies may be the lack of a control group, like the one we had that was instructed just to summarize the presented scenario (i.e., to think factually and not counterfactually) in order to obtain a baseline for comparison. On the other hand, in the present Experiment 1, in which participants were invited to think counterfactually about three given scenarios, we observed more negative associated affects (sadness, feeling negative, feeling bad) in participants who made only upward CT in comparison with those who made only downward CT or both.

Another finding from the study by Juhos et al. (2003) was that participants think that they are more prepared for future similar situations after thinking counterfactually than after thinking factually. What was surprising, and contrary to the initial hypotheses, was that the feeling of preparation after thinking counterfactually about a given scenario was observed in the non-depressed group as well as in the depressed group (also in the present Experiment 1). The proposal that this functional aspect of CT should be different in depressed people can be found in the literature on CT (e.g., Roese \& Olson, 1995c; Sherman \& McConnell, 1995) and it is congruent with the literature on depression (e.g., Beck et al., 1979; Seligman et al., 1979). So, why in those studies did the depressed and non-depressed participants fail to show any differences for feelings of preparation? One possibility is that the result may be due to the type of story (scenario) used. However, in the first experiment presented here, these effects were consistent across the three different scenarios.

A second possibility is that scenarios were not sufficiently involving, and that in a real-life situation one might obtain different results (if not 
at the cognitive/rational level, at least at the behavioural level). It was for this reason that we designed Experiment 2, in which a real-life situation was used instead of a hypothetical scenario, and in which we assessed not only the effects of $\mathrm{CT}$ on cognition (feelings of preparation and of being able to avoid a similar negative result in the future), but also on behavioural intentions and actual behavioural changes 1 week later. Although we did not study a clinical sample, for Experiment 2 we selected students using an even higher cutoff score on the BDI than we used in Experiment 1 (scores between 17 and 22). The results showed that non-depressed participants felt more prepared for future similar situations and more able to avoid future similar negative results after CT than before, but in contrast neither of these effects was found with the depressed participants. Also at the behavioural level, it was observed that the behavioural intentions reported by participants (among the eight given items) with higher scores were: 'study more'; 'work harder'; and 'see the program'. One week later, participants were invited to evaluate actual behavioural changes in the past week. When we checked for significant correlations between intentions and actual behavioural changes, these were found only for the non-depressed group. In general, non-depressed participants intend to work harder and are more likely to convert their intentions into actual behaviour.

In sum, we think that the involving a real-life situation used to study CT in our Experiment 2 finally throws light onto the functional aspects of CT in depression. Depressed participants not only show a lack of cognitive benefits from thinking counterfactually (i.e., after CT they do not feel more prepared for future similar events, nor able to avoid a similar bad outcome, in contrast to the non-depressed participants), as well as a lack of behavioural changes in the sense of intentions to improve. These results fit with the beliefs of depressed people that they are unable to do anything to change their outcomes (see for example Marsh \& Weary, 1994). Even when they correctly identify the cause of the bad outcome (e.g., lack of study) and how to improve in the future (e.g., to study more), as in Experiment 2, they do not benefit from the feeling of preparation and they do not change their behaviour. These findings are congruent with the recent study of Markman and Miller (2006), in which they found that depressed participants obtained no psychological benefit from focusing on how they could prevent a negative outcome.
In our earlier study (Juhos et al., 2003) we did not find differences between depressed and nondepressed individuals on cognitive and affective CT consequences. The results suggested that depressed individuals benefit in the same way from the preparative function of counterfactual thoughts as non-depressed individuals do. Therefore, we proposed that, in a psychotherapeutic context, induced upward CT that results in positive feelings about the future (e.g., being prepared, being able to avoid a failure), could help to overcome the typically negative vision that depressed individuals have about the personal future. However, the present results show that all that occurs for depressed individuals after upward CT is enhanced negative emotion. This effect seems to become more strongly marked with an increase of severity of depression (e.g., Markman \& Miller, 2006). Therefore, CT may help depressed individuals to gain a better understanding of a given situation (Markman \& Weary, 1998), but it does not seem to help them feel better about the future, nor does it help them to prepare better for the future, as we found in Experiment 2.

Finally, these studies will need to be carried out with clinically depressed individuals, not just mildly depressed students, before we can draw final conclusions about the similarities and differences between the function of CT in depressed and non-depressed states. Nevertheless, the current findings are consistent with the clinical literature on depression that shows that depressed individuals may fail to implement skills that are evident when they are not depressed, and that they may experience a state of helplessness and hopelessness towards the future that they approach with a fatalistic sense of foreboding and may bring about the very things that they allegedly fear.

\section{REFERENCES}

Abramson, L.Y., Alloy, L.B., Hankin, B.L., Haeffel, G.J., McCoon, D.G., \& Gibb, B.E. (2002). Cognitive vulnerability-stess models of depression in a self-regulatory psychobiological context. In I.H. Gotlib, \& C.L. Hammen (Eds), Handbook of depression (pp. 268-294). New York: Guilford Press.

Alicke, L.S. (2000). Culpable control and the psychology of blame. Psychological Bulletin, 126, 556-574.

Alloy, L.B., \& Abramson, L.Y. (1979). Judgement of contingency in depressed students: Sadder but wiser? Journal of Experimental Psychology, General, 108, 441485.

Arieti, S. (1974). Interpretation of schizophrenia. London: Crosby, Lockwood \& Staples. 
Beck, A.T. (1976). Cognitive therapy and the emotional disorders. New York: Meridian.

Beck, A.T., Rush, A.S., Shaw, B.F., \& Emery, G. (1979). The cognitive therapy of depression: A treatment manual. New York: The Guilford Press.

Byrne, R.M.J. (1996). Towards a model theory of imaginary thinking. In J. Oakhill \& A. Garnham (Eds), Mental models in cognitive science. Hove: Psychology Press.

Byrne, R.M.J. (1997). Cognitive processes in counterfactual thinking about what might have been. The Psychology of Learning and Motivation, 37, 105-154.

Byrne, R.M.J. (2005). The rational imagination: How people create alternatives to reality. Cambridge: MIT Press.

Champion, L., \& Power, M.J. (1995). Social and cognitive approaches to depression: Towards a new synthesis. British Journal of Clinical Psychology, 34, 485-503.

Davis, C.G., Lehman, D.R., Silver, R.C., Wortman, C.B., \& Ellard, J.H. (1996). Self-blame following a traumatic event: The role of perceived avoidability. Personality and Social Psychology Bulletin, 22, 557-567.

Harvey, A.G., Watkins, E., Mansell, W., \& Shafran, R. (2004). Cognitive behavioural processes across psychological disorders: A transdiagnostic approach to research and treatment. Oxford: Oxford University Press.

Janoff-Bulman, R. (1979). Characterological versus behavioral self-blame: Inquiries into depression and rape. Journal of Personality and Social Psychology, 37, 1798-1809.

Johnson-Laird, P.N. (2006). How we reason. Oxford: Oxford University Press.

Juhos, C., Quelhas, A.C., \& Senos, J. (2003). Pensamento contrafactual na depressão. Psychologica, 32, 199215.

Kocovski, N.L., Endler, N.S., Rector, N.A., \& Flett, G.L. (2005). Ruminative coping and post-event processing in social anxiety. Behaviour Research and Therapy, 43, 971-984.

Kovács, M., \& Beck, A.T. (1978). Maladaptive cognitive structures in depression. American Journal of Psychiatry, $135,525-533$.

Mandel, D.R. (2003). Judgement dissociation theory: An analysis of differences in causal, counterfactual, and covariational reasoning. Journal of Experimental Psychology: General, 132, 419-434.

Mandel, D.R., \& Lehman, D.R. (1996). Counterfactual thinking and ascription of cause and preventability. Journal of Personality and Social Psychology, 71, 450463.

Markman, K.D., \& Miller, A.K. (2006). Depression, control, and counterfactual thinking: Functional for whom? Journal of Social and Clinical Psychology, 25, 210-228.

Markman, K.D., \& Weary, G. (1998). Control motivation, depression, and counterfactual thought. In M. Kofta, \& G. Sedek (Eds), Personal control in action (pp. 363-390). New York: Plenum Press.

Marsh, K.L., \& Weary, G. (1994). Severity of depression and responsiveness to attributional information. Journal of Social and Clinical Psychology, 13, 15-32.

Matte-Blanco, I. (1976). Basic logico-mathematical structures in schizophrenia. In D. Richter (Ed.), Schizophrenia today. Oxford: Pergamon Press.
McMullen, M.N., Markman, K.D., \& Gavanski, I. (1995). Living in neither the best nor worst of all possible words: Antecedents and consequences of upward and downward counterfactual thinking. In N.J. Roese, \& J.M. Olson (Eds), What might have been: The social psychology of counterfactual thinking (pp. 133-169). Mahwah, NJ: Lawrence Erlbaum.

Monroe, M.R., Skowronski, J.J., MacDonald, W., \& Wood, S.E. (2005). The mildly depressed experience more post-decisional regret than the non-depressed. Journal of Social and Clinical Psychology, 24, 665690.

Nolen-Hoeksema, S. (2000). The role of rumination in depressive disorders and mixed anxiety/depressive symptoms. Journal of Abnormal Psychology, 109, 504511.

Power, M.J. (1991). Cognitive science and behavioural psychotherapy: Where behaviour was, there shall cognition be? Behavioural Psychotherapy, 19, 20-41.

Power, M.J., \& Champion, L. (1986). Cognitive approaches to depression: A theoretical critique. British Journal of Clinical Psychology, 25, 201-212.

Power, M.J., \& Dalgleish, T. (2008). Cognition and emotion: From order to disorder (4th ed.). Hove: Psychology Press.

Power, M.J., \& Wykes, T. (1996). The mental health of mental models and the mental models of mental health. In J. Oakhill, \& A. Garnham (Eds), Mental models in cognitive science: Essays in honour of Phil Johnson-Laird (pp. 197-222). Hove: Psychology Press.

Quelhas, A.C. (1987). Mental models and inference errors in paranoid schizophrenic patients. Acta Psychologica Portuguesa, 33, 99-104.

Quelhas, A.C., \& Power, M.J. (1991). Raciocínio dedutivo na depressão. Análise Psicológica, 9, 43-52.

Roese, N.J. (1994). The functional basis of counterfactual thinking. Journal of Personality and Social Psychology, $66,805-818$.

Roese, N.J. (2005). If only. New York: Broadway Books.

Roese, N.J., \& Olson, J.M. (1995a). Outcome controllability and counterfactual thinking. Personality and Social Psychology Bulletin, 21, 620-628.

Roese, N.J., \& Olson, J.M. (Eds) (1995b). What might have been: The social psychology of counterfactual thinking. Mahwah, NJ: Lawrence Erlbaum Associates.

Roese, N.J., \& Olson, J.M. (1995c). Counterfactual thinking: A critical overview. In N.J. Roese, \& J.M. Olson (Eds), What might have been: The social psychology of counterfactual thinking (pp. 1-55). Mahwah, NJ: Lawrence Erlbaum Associates.

Roese, N.J., \& Olson, J.M. (1997). Counterfactual thinking: The intersection of affect and function. In M.P. Zanna (Ed.), Advances in experimental social psychology. San Diego, CA: Academic Press.

Sanna, L.J., Turley-Ames, K.J., \& Meier, S. (1999). Mood, self-esteem, and simulated alternatives: Thought provoking affective influences on counterfactual direction. Journal of Personality and Social Psychology, 76, 543-558.

Seligman, M.E.P., Abramson, L.Y., Semmel, A., \& von Baeyer, C. (1979). Depressive attributional style. Journal of Abnormal Psychology, 88, 242-247. 
Sherman, S.J., \& McConnell, A.R. (1995). Dysfunctional implications of counterfactual thinking: When alternatives to reality fail us. In N.J. Roese, \& J.M. Olson (Eds), What might have been: The social psychology of counterfactual thinking (pp. 199-233). Mahwah, NJ: Lawrence Erlbaum.

Sweeney, P.D., Anderson, C.A., \& Bailey, S. (1986). Attributional style in depression: A meta-analytic review. Journal of Personality and Social Psychology, 50, 974-991.
Weary, G., \& Edwards, J.A. (1994). Social cognition and clinical psychology: Anxiety, depression, and the processing of social information. In T.K. Srull, \& R.S. Wyer (Eds), Handbook of social cognition (Vol. 2, pp. 289-338). NJ: Erlbaum: Hillsdale.

Weary, G., Elbin, S., \& Hill, M.G. (1987). Attributional and social comparison processes in depression. Journal of Personality and Social Psychology, 52, 605610.

\section{APPENDIX A: THE THREE STORIES USED IN EXPERIMENT 1}

\section{Story 1}

When John entered the university, he became immediately a good friend with a girl, one of his colleagues. During a party, they spent the whole time together and their kisses showed the passion that was growing between them.

At the party, John invited her to go to his apartment that was not very far from the university. Initially she refused, but eventually she agreed, though unwilling, giving in due to the persistence of John.

Before they left, John remembered that in the toilet he had seen a machine where he could buy some condoms. He asked her to wait a little and went to the toilet to buy a box of condoms, but the machine was out of order.

At John's apartment, everything happened very quickly and the two teenagers made love without using a condom. A week later both of them complained that they had a very unpleasant sensation in the genital area. After a medical examination, they were told that they had a microbial infection that is transmitted through sexual intercourse and the cure for this infection requires medical treatment.

Story 2

Sarah, a psychology student, had three days to study for the exam of Psychopathology. She knows that if she manages her time she can even get a good grade. It is very important for her to have, at least, a 12 , so that her course average will allow her to choose, next year, the specialization area that she likes the most.

Friday, Sarah went to ISPA to copy an important paper in order to study it during the weekend. As she entered the building, she remembered that she had to go to the students association and ask if they had sample exams from previous years.

When she went to the library, she saw that the library director decided that the library had to be closed two hours earlier than usual; this way it was impossible to copy the paper.

The exam turned out badly because she had not read the paper. When she saw the grades, she realised that she had only got almost a negative grade.

\section{Story 3}

Anna was a close friend of a boy, a high school colleague, for a long time and recently they started to date. After they had started to date, they were always together and had many plans for the future.

Meanwhile, Anna decided that in August they would not spend their holidays together as a way of testing the trust in their relationship.

Anna's boyfriend, a little annoyed with her decision, decided that he would not answer her phone calls during that month.

When they met again in September, she was informed that he had found himself another girlfriend in August; this led to an intense discussion between them. Though they broke up, they continued to be friends. 


\section{APPENDIX B: MATERIALS FOR EXPERIMENT 2}

In Experiment 2, participants received a book containing:

- On page 1 Participant identification: age, gender and student number.

- On page 2 Evaluation of general emotional state (how good do you feel? 1-not at all, 9-very much; how bad do you feel, same ratings); evaluation of the intensity of specific emotions chosen from a list of 12 emotions (self-realization, satisfaction, happiness, joy, confidence, hope, regret, sadness, guilt, disappointment, shame, anger; 1 -minim., 9-max.).

- On page 3 Participants are asked to record five spontaneous thoughts that occurred to them right after they were informed of the result.

- On page 4 Participants evaluate their feelings in relation to being prepared for a similar situation in the future and in relation to their ability to avoid future negative results. Intensity of feelings was measured on a nine-point rating scale, where the extremes were: 1 - I do not agree at all and 9-I agree completely. In both cases participants were asked to justify their ratings.

- On page 5 Participants evaluated the intensity of emotion on a nine-point rating scale (1-minim; 9-max). They began with general emotions (feeling good/bad) and then chose specific emotions from the same list of 12 as on page 2 .

- On page 6 Participants were induced to think counterfactually about the situation and then write down their thoughts.

- On page 7 Participants were asked how prepared they feel for the future and how capable they feel to avoid future negative results after thinking about how things could have been different (ratings on nine-point scales). Participants were asked to justify their ratings.

- On page 8 Same as page 5.

- On page 9 Participants recorded their behavioural intentions using nine point rating scales (1certainly won't do this; 9-certainly will do this) on items like 'Study more', 'Work harder' and 'Guide my study using the program of the course'. 